\title{
N-Acetylglucosamine Induces White to Opaque Switching, a Mating Prerequisite in Candida albicans
}

\author{
Guanghua Huang, Song Yi, Nidhi Sahni, Karla J. Daniels, Thyagarajan Srikantha, David R. Soll*
}

Department of Biology, The University of lowa, lowa City, lowa, United States of America

\begin{abstract}
To mate, the fungal pathogen Candida albicans must undergo homozygosis at the mating-type locus and then switch from the white to opaque phenotype. Paradoxically, opaque cells were found to be unstable at physiological temperature, suggesting that mating had little chance of occurring in the host, the main niche of $C$. albicans. Recently, however, it was demonstrated that high levels of $\mathrm{CO}_{2}$, equivalent to those found in the host gastrointestinal tract and select tissues, induced the white to opaque switch at physiological temperature, providing a possible resolution to the paradox. Here, we demonstrate that a second signal, N-acetylglucosamine (GICNAC), a monosaccharide produced primarily by gastrointestinal tract bacteria, also serves as a potent inducer of white to opaque switching and functions primarily through the Ras $1 / \mathrm{cAMP}$ pathway and phosphorylated Wor1, the gene product of the master switch locus. Our results therefore suggest that signals produced by bacterial co-members of the gastrointestinal tract microbiota regulate switching and therefore mating of $C$. albicans.
\end{abstract}

Citation: Huang G, Yi S, Sahni N, Daniels KJ, Srikantha T, et al. (2010) N-Acetylglucosamine Induces White to Opaque Switching, a Mating Prerequisite in Candida albicans. PLoS Pathog 6(3): e1000806. doi:10.1371/journal.ppat.1000806

Editor: Christina M. Hull, University of Wisconsin-Madison, United States of America

Received November 2, 2009; Accepted February 3, 2010; Published March 12, 2010

Copyright: (C) 2010 Huang et al. This is an open-access article distributed under the terms of the Creative Commons Attribution License, which permits unrestricted use, distribution, and reproduction in any medium, provided the original author and source are credited.

Funding: This research was funded by the Developmental Studies Hybridoma Bank-Microbe at the University of lowa. The funders had no role in study design data collection and analysis, decision to publish, or preparation of the manuscript.

Competing Interests: The authors have declared that no competing interests exist.

*E-mail: david-soll@uiowa.edu

\section{Introduction}

The white-opaque transition in MTL-homozygous strains of Candida albicans affects cellular physiology, cell morphology, gene expression, virulence and biofilm formation [1-3]. It is repressed by the $\mathbf{a} 1-\alpha 2$ co-repressor in $\mathbf{a} / \alpha$ cells and derepressed in cells that have undergone $M T L$-homozygosis to become either $\mathbf{a} / \mathbf{a}$ or $\alpha / \alpha$ [4]. White-opaque switching, which occurs spontaneously and reversibly, is controlled through expression of a master switch locus, WOR1, which also has been referred to as TOS9 [5-7]. The frequency of switching is regulated in part at the level of WOR1 transcription by a number of genes through a network of positive and negative regulatory loops $[8,9]$ and through changes in chromatin state [10-12].

After the discovery of a mating system in C. albicans [13], it was demonstrated that MTL-homozygous cells had to switch from white to opaque in order to mate [4,14]. Paradoxically, it was demonstrated that in vitro this switch was sensitive to physiological temperature $[15,16]$. When the temperature of opaque cell cultures grown at $25^{\circ} \mathrm{C}$ was raised to $37^{\circ} \mathrm{C}$, cells switched en masse and semi-synchronously to white [17], suggesting that the opaque phenotype was unstable at physiological temperatures and that mating would, therefore, be compromised in a host, the major niche of $C$. albicans. Recently, we demonstrated that high levels of $\mathrm{CO}_{2}$ comparable to those found in the host gastrointestinal tract and some host tissues induced switching from white to opaque, maintained cells in the opaque phenotype, and blocked switching from opaque to white [18]. $\mathrm{CO}_{2}$ had been demonstrated previously to be a potent inducer of filamentation as well $[19,20]$. Because N-acetylglucosamine (GlcNAc), which is produced by bacteria in the gastrointestinal tract [21], is also a potent inducer of filamentation [22], we therefore considered the possibility that it, like $\mathrm{CO}_{2}$, was an inducer of the white to opaque transition.

We found that G1cNAc represents a second strong inducer of the white to opaque transition and stabilizes the opaque phenotype. GlcNAc induction occurs at $25^{\circ} \mathrm{C}$ and is enhanced at $37^{\circ} \mathrm{C}$. In addition, because there were indications that the induction of filamentation by GlcNAc was mediated by the Rasl/cAMP pathway [23-30], we tested whether GlcNAc induction of switching was regulated by this pathway. Our results demonstrate that GlcNAc induction is transduced primarily by the same Rasl/cAMP pathway that has been implicated in the regulation of filamentation and requires phosphorylated Wor 1 , the product of the master switch locus. We therefore suggest that two different signals in the host gastrointestinal tract, both produced by bacterial co-members of the gastrointestinal tract microbiota, can regulate the white to opaque transition, an essential step in $C$. albicans mating.

\section{Results}

\section{GIcNAc Induction of Switching}

To test whether GlcNAc induces the white to opaque transition and does so as a function of culture age, as is the case for the induction of filamentation [22,24], white cells of $\mathbf{a} / \mathbf{a}$ and $\alpha / \alpha$ derivatives of strain SC5314, 5314a and $5314 \alpha$, respectively, were first grown at $25^{\circ} \mathrm{C}$ in suspension in liquid modified Lee's medium in which glucose was the sole carbon source ("liquid glucose medium") [31] (Figure 1A). To assess GlcNAc induction as a function of culture growth [23], cells were removed at time intervals from the liquid culture, plated on nutrient agar containing either 


\section{Author Summary}

To mate, the human fungal pathogen Candida albicans must undergo a complex phenotypic change from a round "white" to large, elongated "opaque" cell. This involves the regulation of approximately 5\% of the organism's genes. Surprisingly, this complex transition is not required for mating in other related yeast. Even more surprisingly, it was found that in vitro the mating-competent opaque phenotype was unstable at $37^{\circ} \mathrm{C}$, the temperature of the host body. This observation led to a paradox. If $C$. albicans lives primarily in an animal host, physiological temperature would thwart mating, so where does $C$. albicans mate? This led to the suggestion that some physiological condition in the host niche stabilizes the opaque phenotype or even induces switching from white to opaque, so cells can mate. Recently, we demonstrated that the high concentrations of $\mathrm{CO}_{2}$ found in tissue and the gastrointestinal tract induced switching from white to opaque and then stabilized the opaque phenotype. Here, we demonstrate that a second factor, N-acetylglucosamine (GlcNAc), a sugar released primarily by bacteria in the gastrointestinal tract, also induces the switch from white to opaque and stabilizes the opaque phenotype. We demonstrate by mutational analysis that GICNAc induction is regulated primarily by the Ras1/cAMP pathway, which also regulates filamentation of $C$. albicans. This is perhaps not surprising given that white-opaque switching shares with filamentation several phenotypic characteristics. Finally, we show that induction by GICNAc requires the phosphorylated master switch gene that regulates spontaneous switching, suggesting that it induces the switch from white to opaque by activating the gene product of the master switch gene. Together, our results suggest that multiple signals from bacterial co-members of the gastrointestinal tract microbiota regulate switching and, therefore, mating of $C$. albicans in the colonized host.

$1.25 \%(\mathrm{w} / \mathrm{v})$ glucose ("glucose agar") or $1.25 \%(\mathrm{w} / \mathrm{v})$ GlcNAc ("GlcNAc agar") as the sole carbon source (Figure 1A), and incubated at $25^{\circ} \mathrm{C}$. This temperature was selected to assess induction initially, because physiological temperature $\left(37^{\circ} \mathrm{C}\right)$ induces the reverse switch from opaque to white $[15,17]$, and we wanted the initial assessment to be performed in the absence of reverse induction. After five days on agar, the proportion of opaque colonies plus white colonies with opaque sectors was measured in glucose or GlcNAc agar. This proportion will be referred to as the "switching frequency" for convenience, but should not be confused with the rate of switching $[1,16,32]$. Although $\mathbf{a} / \mathbf{a}$ and $\alpha / \alpha$ cultures reached different final cell densities, they entered the saturation phase in liquid glucose medium at approximately the same time (Figure 1B).

For $\mathbf{a} / \mathbf{a}$ cells plated on glucose agar at $25^{\circ} \mathrm{C}$, the switching frequency increased from $0.4 \pm 0.4 \%$ for cells taken from exponential phase cultures after one day, to $3.5 \pm 1.2 \%$ for cells taken from late saturation phase cultures after 10 days (Figure 1C, D). For $\alpha / \alpha$ cells, the proportion increased similarly from $0.5 \pm 0.5 \%$ to $2.9 \pm 0.2 \%$ (Figure $1 \mathrm{C}, \mathrm{D}$ ). Hence, the switching frequency of $\mathbf{a} / \mathbf{a}$ and $\alpha / \alpha$ cells grown in liquid glucose medium increased 9.5- and 6.0-fold, respectively, over the course of exponential growth and entrance into the saturation phase. For a/ a cells plated on GlcNAc agar, the frequency of switching increased from $5.1 \pm 1.3 \%$ after one day to $88.7 \pm 4.9 \%$ after 10 days, and for $\alpha / \alpha$ cells, the frequency increased from $7.3 \pm 3.4 \%$ to $92.5 \pm 3.3 \%$ (Figure 1C, D). Plating on GlcNAc agar, therefore, caused an increase in the frequency of switching of $\mathbf{a} / \mathbf{a}$ and $\alpha / \alpha$ cells after one day that was approximately 13- and 15-fold higher, respectively, than the frequencies on glucose agar after one day (Figure 1C, D). After 10 days, the frequency was 25- and 32-fold higher, respectively, than the frequency on glucose agar (Figure 1C, D). In Figure 1E, examples are presented of cultures from three day liquid glucose cultures of $\mathbf{a} / \mathbf{a}$ cells plated on glucose agar or GlcNAc agar. Note that on GlcNAc agar, the majority of colonies were completely opaque rather than sectored, indicating that in these cases GlcNAc induction occurred very early in the life history of the colonies. Similar results were obtained for cells grown in liquid glucose medium for five days and plated on agar containing either glucose or GlcNAc ranging in concentration from $0.2 \%$ to $5 \%(\mathrm{w} / \mathrm{v})$, indicating that the concentration employed $(1.25 \%$, w/v) resulted in maximum GlcNAc induction (data not shown).

\section{GlcNAc Induction at $37^{\circ} \mathrm{C}$}

The preceding experiments were performed at $25^{\circ} \mathrm{C}$. To test whether GlcNAc also induced white to opaque switching at physiological temperature $\left(37^{\circ} \mathrm{C}\right)$, we then performed experiments in which white cells of $\mathbf{a} / \mathbf{a}$ and $\alpha / \alpha$ derivatives of strain SC5314 were grown to mid-log phase on liquid glucose medium for $48 \mathrm{hr}$ at $25^{\circ} \mathrm{C}$, then plated on glucose or GlcNAc agar at either 25 or $37^{\circ} \mathrm{C}$. Increasing the temperature from 25 to $37^{\circ} \mathrm{C}$ on glucose agar resulted in a lower frequency of switching for white cells of both the $\mathbf{a} / \mathbf{a}$ and $\alpha / \alpha$ strains (Table 1 , data in air). In direct contrast, when white cells of both strains were grown in liquid glucose medium at $25^{\circ} \mathrm{C}$ and then plated on GlcNAc agar at $37^{\circ} \mathrm{C}$, there was a dramatic increase in the switching frequency (Table 1, data in air). These data demonstrate that physiological temperature enhances GlcNAc induction.

\section{The Role of Ras1}

The cAMP pathway, which plays a role in filamentation, includes Ras1, Cdc35, Pde2 and the protein kinase isoforms Tpk1 and Tpk2 [25-30]. To test whether GlcNAc induction of white to opaque switching was mediated by the cAMP pathway, we first analyzed the $R A S 1$ deletion mutant, ras $1 /$ ras 1 . These experiments were performed at $25^{\circ} \mathrm{C}$ because a temperature of $37^{\circ} \mathrm{C}$ induced a portion of the cells of mutants of the Ras1/cAMP pathway to undergo filamentation (data not shown), making it difficult to assess switching from white to opaque at the level of cell phenotype. White cells of ras $1 /$ ras 1 and the control strain (WT) were grown at $25^{\circ} \mathrm{C}$ in liquid glucose medium to saturation phase (seven days), plated on either glucose or GlcNAc agar, and analyzed for switching frequencies after five days at $25^{\circ} \mathrm{C}$. The switching frequency on GlcNAc agar was 90.5 $\pm 3.8 \%$ for WT cells, and $11.2 \pm 1.5 \%$ for ras $1 /$ ras 1 cells (Figure $2 \mathrm{~A}$ ), indicating that Rasl played a major, but not exclusive, role in GlcNAc induction. The frequency of switching of ras $1 /$ ras 1 cells on GlcNAc agar was 9-fold lower than that of WT cells, and 16fold higher than that on glucose agar (Figure 2A). Complementation of ras $1 /$ ras 1 with RAS1 under the control of the MET3 promoter partially rescued the mutant phenotype in the activated state (Figure 2A). Rescue was incomplete due to the fact that RAS1 was controlled in the complemented strain by the MET3 rather than the natural promoter $[7,33]$. It should also be noted that on glucose agar, the frequency of switching of WT cells was two-fold higher than that of ras $1 /$ ras 1 cells (Figure 2A), indicating that a RAS1-dependent pathway also played a role in spontaneous switching on glucose agar.

To explore further the role of RAS1 in GlcNAc induction, we transformed strain WUM5A, a derivative of $\alpha / \alpha$ strain WO-1, 


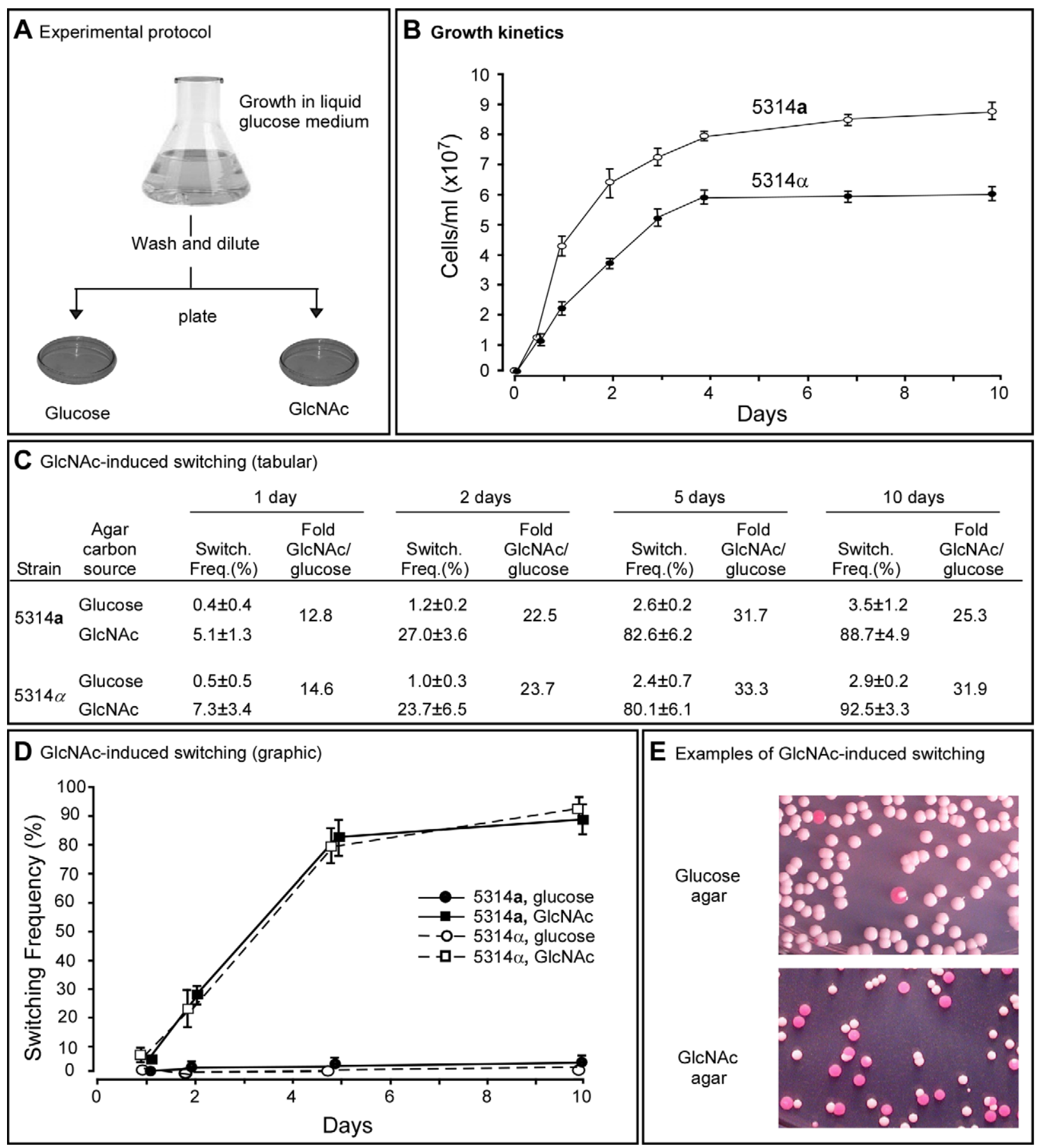

Figure 1. GlcNAc induces switching from white to opaque in a and $\alpha$ cells of Candida albicans. A. The experimental protocol for assessing GlcNAC induction. Cells are first grown in liquid glucose medium at $25^{\circ} \mathrm{C}$ and then plated on glucose or GlcNAc agar at $25^{\circ} \mathrm{C}$ and in select cases at $37^{\circ} \mathrm{C}$. B. Growth kinetics of a and $\alpha$ cells in liquid glucose medium at $25^{\circ} \mathrm{C}$. C. Switching frequencies (Switch. Freq.) on glucose or GlcNAc agar of cells grown at $25^{\circ} \mathrm{C}$ in liquid glucose medium for 1, 2, 5 and 10 days. The colony number assessed for phenotype varied between 370 and 700 under the varied conditions. D. A graph of the switching frequencies from panel C. E. Examples of 3 day cultures on glucose or GlcNAc agar at $25^{\circ} \mathrm{C}$. Switching frequencies were measured after 5 days on agar. No. Cols., number of colonies.

doi:10.1371/journal.ppat.1000806.g001

with RAS1V13, which encodes a constitutively activated form of Ras1 (Ras1V13 [25]) under the control of the MET3 promoter MET3p [33], to generate strain WT+MET3p-RAS1V13. The control strain was also transformed with the vector lacking the RAS1V13 to generate the control strain WT+vector. The addition of $2.5 \mathrm{mM}$ methionine plus $2.5 \mathrm{mM}$ cysteine (+Met, +Cys) represses MET3 promoter activity (the repressed state) and the absence (-Met, -Cys) activates it (the activated state) [33]. White cells of WT+METp-RAS1V13 and WT+vector were plated directly onto glucose agar in the presence or absence of methionine and cysteine at $25^{\circ} \mathrm{C}$. In the repressed state (+Met, + Cys), the majority of colonies were white, with few sectors, but in the activated state (-Met, -Cys), nearly every colony was highly sectored (Figure 2B), indicating that overexpression of RAS1V13 in the absence of 
Table 1. GlcNAc induction of white-to-opaque switching is enhanced at $37^{\circ} \mathrm{C}$ and in $1 \% \mathrm{CO}_{2}$.

\begin{tabular}{|c|c|c|c|}
\hline \multirow[t]{2}{*}{ Strain } & \multirow[t]{2}{*}{$\begin{array}{l}\text { Agar Medium, } \\
\text { Temp }\end{array}$} & \multirow{2}{*}{$\begin{array}{l}\text { Air } \\
\text { Switching } \\
\text { frequency (\%) }\end{array}$} & \multirow{2}{*}{$\begin{array}{l}1 \% \mathrm{CO}_{2} \\
\text { Switching } \\
\text { frequency (\%) }\end{array}$} \\
\hline & & & \\
\hline \multirow[t]{4}{*}{$5314 a$} & Glucose, $25^{\circ} \mathrm{C}$ & $0.4 \pm 0.6$ & $21.4 \pm 1.4$ \\
\hline & $37^{\circ} \mathrm{C}$ & $<0.4$ & $7.5 \pm 1.5$ \\
\hline & $\mathrm{GlcNAc}, 25^{\circ} \mathrm{C}$ & $26.7 \pm 1.2$ & $100.0 \pm 0.0$ \\
\hline & $37^{\circ} \mathrm{C}$ & $98.9 \pm 1.2$ & $100.0 \pm 0.0$ \\
\hline \multirow[t]{4}{*}{$5314 \alpha$} & Glucose, $25^{\circ} \mathrm{C}$ & $0.2 \pm 0.4$ & $19.4 \pm 1.8$ \\
\hline & $37^{\circ} \mathrm{C}$ & $<0.2$ & $7.1 \pm 0.5$ \\
\hline & $\mathrm{GlcNAc}, 25^{\circ} \mathrm{C}$ & $22.4 \pm 3.3$ & $100.0 \pm 0.0$ \\
\hline & $37^{\circ} \mathrm{C}$ & $99.7 \pm 0.6$ & $99.4 \pm 0.5$ \\
\hline
\end{tabular}

As described in Figure 1A, white cells were cultured for 48 hours in glucose liquid medium at $25^{\circ} \mathrm{C}$, then plated onto glucose or GlcNAc agar, and incubated at 25 or $37^{\circ} \mathrm{C}$ in air or air containing $1 \% \mathrm{CO}_{2}$. Total colonies analyzed in each strain and condition varied between 150 and 400 .

doi:10.1371/journal.ppat.1000806.t001

GlcNAc induced switching. Next, white cells of strains WT+vector and WT+METp-RAS1V13 were grown in liquid glucose medium in the repressed state for one day to the mid-exponential phase, then plated on either glucose or GlcNAc agar in the induced state. On glucose agar, the switching frequency of white WT+vector cells was $2.1 \pm 1.0 \%$, and for the overexpression strain, $100 \%$ (Figure 2C). The majority of colonies of the overexpression mutant on glucose agar were highly sectored white colonies (Figure 2D). Only $2.3 \pm 1.2 \%$ were homogeneous opaque colonies. On GlcNAc agar, the switching frequency of control cells was $3.2 \pm 0.2 \%$, while that of the overexpression mutant was $100 \%$ (Figure 2C). All of the latter colonies were homogeneously opaque (Figure 2D). The near uniformity of the opaque phenotype in the latter colonies was evident at the cellular level (Figure 2E). These results reinforce the conclusion that induction of white to opaque switching by GlcNAc is mediated primarily by Rasl.

\section{The Role of cAMP}

In the cAMP pathway that is involved in filamentation, Ras 1 activates adenylate cyclase, which is encoded by CDC35 [26]. The resulting increase in cAMP is kept in check by a cAMPphosphodiesterase, which is encoded by PDE2 [34,35]. If GlcNAc induction of white-opaque switching is mediated by the same cAMP pathway, then deletion of CDC35 should reduce the effect, while deletion of PDE2 should enhance it. When white $c d c 35 / c d c 35$ cells were grown at $25^{\circ} \mathrm{C}$ to saturation phase in liquid glucose medium (seven days) and then plated on GlcNAc agar, the frequency of switching was $8.0 \pm 3.5 \%$, whereas that of the WT parental control was $86.9 \pm 4.3 \%$ (Figure 3A). Complementation of the mutant $c d c 35 / c d c 35$ with CDC35 under control of the MET3 promoter partially rescued the mutant phenotype (Figure 3A). These results indicate that $C D C 35$ is necessary for the major response to GlcNAc, as was the case for RAS1. GlcNAc did, however, induce low level switching in white $c d c 35 / c d c 35$ cells, indicating that although CDC35 is necessary for the major response to GlcNAc, there is a minor response that is CDC35independent, just as we observed there is a minor response that is RAS1-independent.

When white $p d e 2 / p d e 2$ cells were grown at $25^{\circ} \mathrm{C}$ to saturation phase in liquid glucose medium (five days) and then plated on
GlcNAc agar, the switching frequency was $100 \%$, compared to $78.6 \pm 6.5 \%$ for control cells (Figure $3 \mathrm{~A}$ ). When plated on glucose agar, the frequency of switching was $96.0 \pm 1.5 \%$, compared to $0.6 \pm 0.6$ for WT cells (Figure 3A). Complementation of the pde $2 /$ pde2 mutant with PDE2 under the control of the MET3 promoter partially rescued the mutant phenotype (Figure 3A).

To explore further the role of Pde2 in switching, the deletion mutant $p d e 2 / p d e 2$ was also transformed with a vector containing $P D E 2$ under the control of the MET3 promoter to generate the strain $p d e 2 / p d e 2+M E T 3 p-P D E 2$. The deletion mutant $p d e 2 / p d e 2$ was transformed with the vector lacking $P D E 2$ to generate the control strain $p d e 2 / p d e 2+$ vector. When white cells of the parental control (WT) were grown at $25^{\circ} \mathrm{C}$ as a streak on glucose agar lacking methionine and cysteine (activating conditions), only rare opaque sectors formed at the periphery (Figure 3B). When the mutant $p d e 2 / p d e 2+$ vector was streaked at $25^{\circ} \mathrm{C}$, opaque sectors rimmed the entire streak (Figure $3 \mathrm{~B}$ ). In contrast, opaque sectors were absent at the periphery of the streak of the overexpression mutant $p d e 2 / p d e 2+M E T 3 p-P D E$ under activating conditions (Figure 3B). When the overexpression mutant pde2/pde2+ $M E T 3 p-P D E$ was grown at $25^{\circ} \mathrm{C}$ in liquid glucose medium under activating conditions to early exponential phase (two days), then plated on glucose agar at $25^{\circ} \mathrm{C}$ under activating conditions, the frequency of sectoring was $2.8 \pm 1.2 \%$, compared to $98.9 \pm 1.9 \%$ for the deletion mutant (Figure 3C). When plated at $25^{\circ} \mathrm{C}$ on GlcNAc agar under activating conditions, the frequency of switching of the rescued strain was $26.8 \pm 5.8 \%$ compared to $100 \%$ for the mutant (Figure 3C). Examples of colonies of strain $p d e 2 / p d e 2+$ vector and $p d e 2 / p d e 2+M E T 3 p-P D E$ grown at $25^{\circ} \mathrm{C}$ on glucose or GlcNAc agar under activating conditions are presented in Figure 3D, and examples of cells from these colonies are presented in Figure 3E. These results support the conclusion that cAMP is involved in the regulation of the GlcNAc response and that Pde2 plays the role of a negative regular.

\section{The Role of the Protein Kinases}

In the Ras1/cAMP pathway, cAMP activates protein kinase A (PKA) [27,36]. In $S$. cerevisiae there are three PKA catalytic subunits, Tpk1, Tpk2 and Tpk3, which play roles in the cAMP pathway regulating pseudohypha formation [36,37]. C. albicans possesses two isoforms, Tpk1 and $\mathrm{Tpk} 2$, which have been demonstrated to play functionally different roles in filamentation, depending upon environmental conditions [27,38]. Consistent with previous reports [27], our lack of success in generating a double mutant of TPK1 and TPK2 suggested that this mutant may not be viable. We therefore analyzed the individual deletion mutants $t p k 1 / t p k 1$ and $t p k 2 / t p k 2$. White cells of the individual deletion mutants were grown at $25^{\circ} \mathrm{C}$ in liquid glucose medium to saturation phase (seven days) and then plated on glucose or GlcNAc agar and examined for switching after five days. Deletion of either TPK1 or TPK2 had no detectable effect on the frequency of switching on glucose or on GlcNAc agar (Figure 3F). There was, however, one noticeable difference in the GlcNAc-induced opaque colonies of tpk1/tpk1. They possessed a mixture of opaque cells and cells that had formed hyphae, suggesting that Tpkl plays a role in the regulation of the bud-hyphae transition (data not shown).

Given that each of the alternative PKA isoforms may perform redundant function in the two mutants $t p k 1 / t p k 1$ or $t p k 2 / t p k 2$, we generated overexpression mutants in the wild type background WUM5A (WT) in which TPK1 or TPK2 was placed under the regulation of the strong constitutive $A C T 1$ promoter [5]. White cells of the overexpression strains WT+ACTp-TPK1 and $\mathrm{WT}+A C T p$-TPK2, as well as white cells of the control strain, were grown for five days at $25^{\circ} \mathrm{C}$ to saturation phase in liquid glucose 


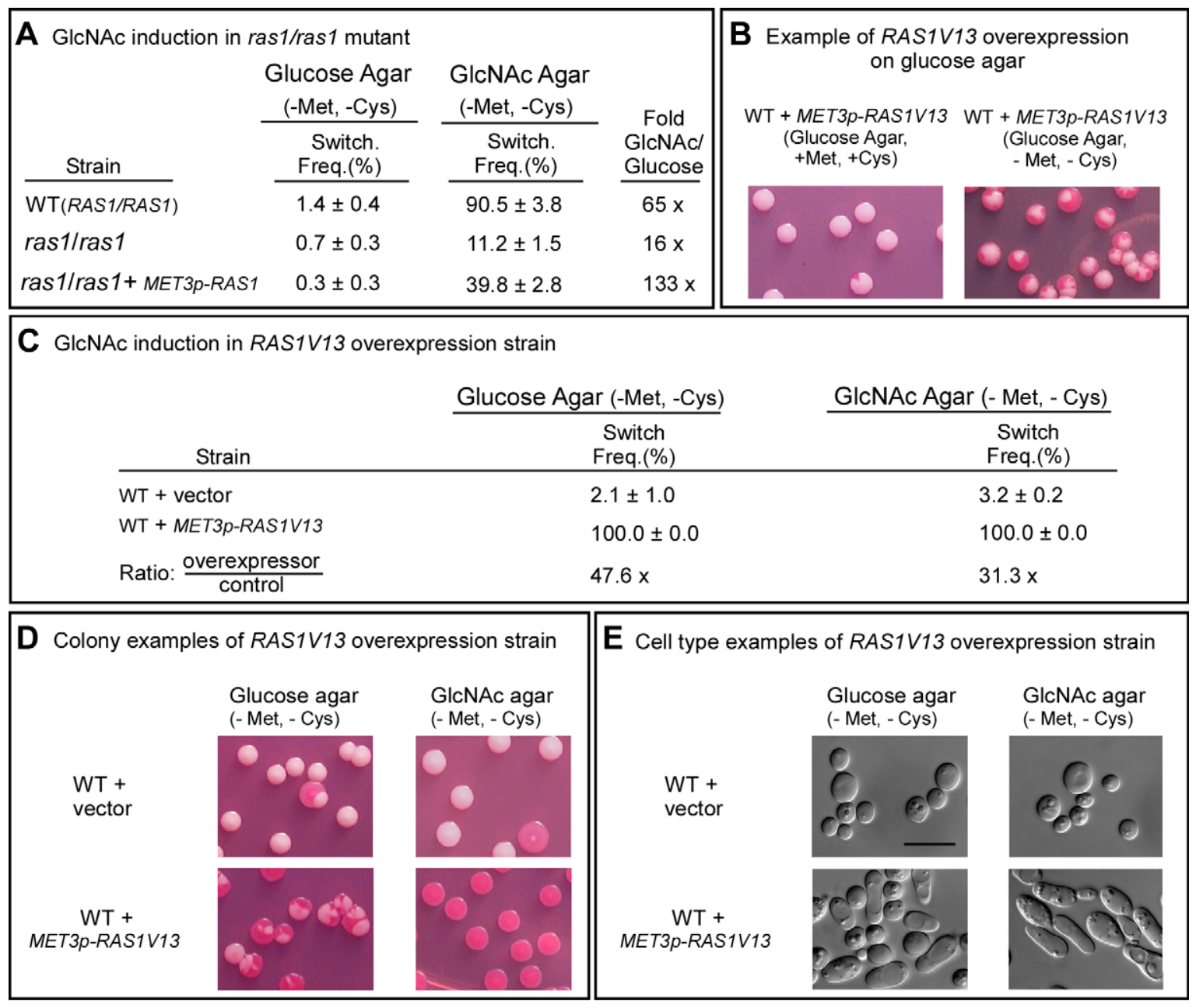

Figure 2. Ras 1 plays a major role in GIcNAc induction. A. Switching frequencies (Switch. Freq.) of wild type (WT) and ras $1 /$ ras 1 cells grown in a glucose liquid medium at $25^{\circ} \mathrm{C}$ for 7 days and then plated on glucose agar and GlcNAc agar at $25^{\circ} \mathrm{C}$. The colony numbers assessed for phenotype varied between 600 and 1,000 under varied conditions. B. Colonies of the inducible strain WT+MET3p-RAS1V13 grown on glucose at $25^{\circ} \mathrm{C}$ agar in the presence (repressing condition) or absence (activating condition) of methionine and cysteine. White cells from glucose agar (repressing condition) were plated. C. Switching frequencies of cells of the control strain WT+vector and the RAS1V13 overexpression strain WT+MET3p-RAS1V13 grown at $25^{\circ} \mathrm{C}$ in glucose liquid medium for one day and then plated on glucose or GlcNAc agar at $25^{\circ} \mathrm{C}$. The colony numbers assessed ranged between 250 and 400. D. Examples of colonies on glucose and GlcNAc agar under activating conditions. E. Examples of cells from colonies on glucose and GlcNAc agar at $25^{\circ} \mathrm{C}$ under activating conditions. The scale bars in panel E represents $10 \mu \mathrm{m}$. Switching frequencies were measured after 5 days of growth at $25^{\circ} \mathrm{C}$ on agar.

doi:10.1371/journal.ppat.1000806.g002

medium and then plated on glucose or GlcNAc agar and examined after five days at $25^{\circ} \mathrm{C}$ for switching (Figure $1 \mathrm{~A}$ ). Overexpression of TPK1 had no effect on the switching frequency on glucose agar and actually suppressed switching on GlcNAc agar (Figure 3F). Overexpression of TPK2, however, caused a tenfold increase in the switching frequency on glucose agar over that of wild type cells and enhanced the frequency of switching by approximately $20 \%$ on GlcNAc agar (Figure 3F). These results suggested that in wild type cells, Tpk2 may function as the major downstream kinase in the GlcNAc induction pathway.

\section{Ras1/cAMP Pathway at $37^{\circ} \mathrm{C}$}

At $37^{\circ} \mathrm{C}$, GlcNAc induction was impaired in the mutants ras $1 /$ ras 1 and $c d c 35 / c d c 35$ (supplemental Table S1) but to a lesser extent than at $25^{\circ} \mathrm{C}$. High temperature induction, however, reinforced our conclusion that it is Tpk2 that plays the crucial role in wild type cells in transducing GlcNAc induction. Whereas at $25^{\circ} \mathrm{C}$ GlcNAc induction was unaffected in tpk1/tpk1 and tpk2/tpk2, at $37^{\circ} \mathrm{C}$ it was reduced in the tpk2/tpk2, but not tpk1/tpk1 (supplemental Table S1). These results supported our conclusion based on overexpression data (Figure 3B-E) that Tpk2 plays a role in transducing GlcNAc induction in wild type cells.

\section{The Role of WOR1}

The WOR1 (TOS9) locus has been demonstrated to regulate spontaneous white-opaque switching [5-7]. It has been proposed that a stochastic increase in WOR1 expression above a threshold causes cells to switch from white to opaque, and that continued expression above that threshold maintains the opaque phenotype [5-7]. Wor 1 has been shown to auto-induce at the level of transcription [5-7]. When activated, the cAMP pathway, which traditionally functions by cAMP-activation of protein kinase A, might increase the frequency of switching by phosphorylating either Worl or one of the several proteins that modulate WOR1 function through transcriptional regulatory loops $[8,9]$ or chromatin modification [10-12]. Interestingly, Worl possesses a single consensus PKA phosphorylation motif, 


\begin{tabular}{|c|c|c|}
\hline \multicolumn{3}{|c|}{$\begin{array}{l}\text { A GlcNAc induction in cdc35/cdc35 and } \\
\text { pde2pde2 mutants }\end{array}$} \\
\hline & $\begin{array}{l}\text { Glucose agar } \\
\text { (-Met, -Cys) }\end{array}$ & $\begin{array}{l}\text { GlcNAc agar } \\
\text { (-Met, -Cys) }\end{array}$ \\
\hline Strain & Switch. Freq. $(\%)$ & $\overline{\text { Switch. Freq. (\%) }}$ \\
\hline WT(GH1013) & $0.6 \pm 0.5$ & $86.9 \pm 4.3$ \\
\hline$c d c 35 / c d c 35$ & $<0.3$ & $8.0 \pm 3.5$ \\
\hline $\begin{array}{l}c d c 35 / c d c 35 \\
+M E T 3 p-C D C 35\end{array}$ & $0.3 \pm 0.3$ & $21.5 \pm 5.1$ \\
\hline WT(WUM5A) & $0.6 \pm 0.6$ & $78.3 \pm 6.5$ \\
\hline pde2/pde2 & $96.0 \pm 1.5$ & $100.0 \pm 0.0$ \\
\hline $\begin{array}{c}\text { pde2/pde2 } \\
+ \text { MET3p-PDE2 }\end{array}$ & $2.3 \pm 0.8$ & $29.3 \pm 1.9$ \\
\hline
\end{tabular}

B Example of patches on agar

C GlcNAc induction in pde2pde2 mutant (2 day cultures in liquid)

\begin{tabular}{lcc} 
& Glucose Agar (-Met, -Cys) & GlcNAc Agar (- Met, - Cys) \\
\cline { 2 - 3 } \multicolumn{1}{c}{ Strain } & Switch. Freq.(\%) & Switch. Freq.(\%) \\
\hline pde2/pde2 + Vector & $98.9 \pm 1.9$ & $100.0 \pm 0.0$ \\
pde2/pde2 + MET3p-PDE2 & $2.8 \pm 1.2$ & $26.8 \pm 5.8$ \\
Ratio: $\frac{\text { mutant }}{\text { rescued strain }}$ & $34.2 \times$ & $3.7 \times$
\end{tabular}

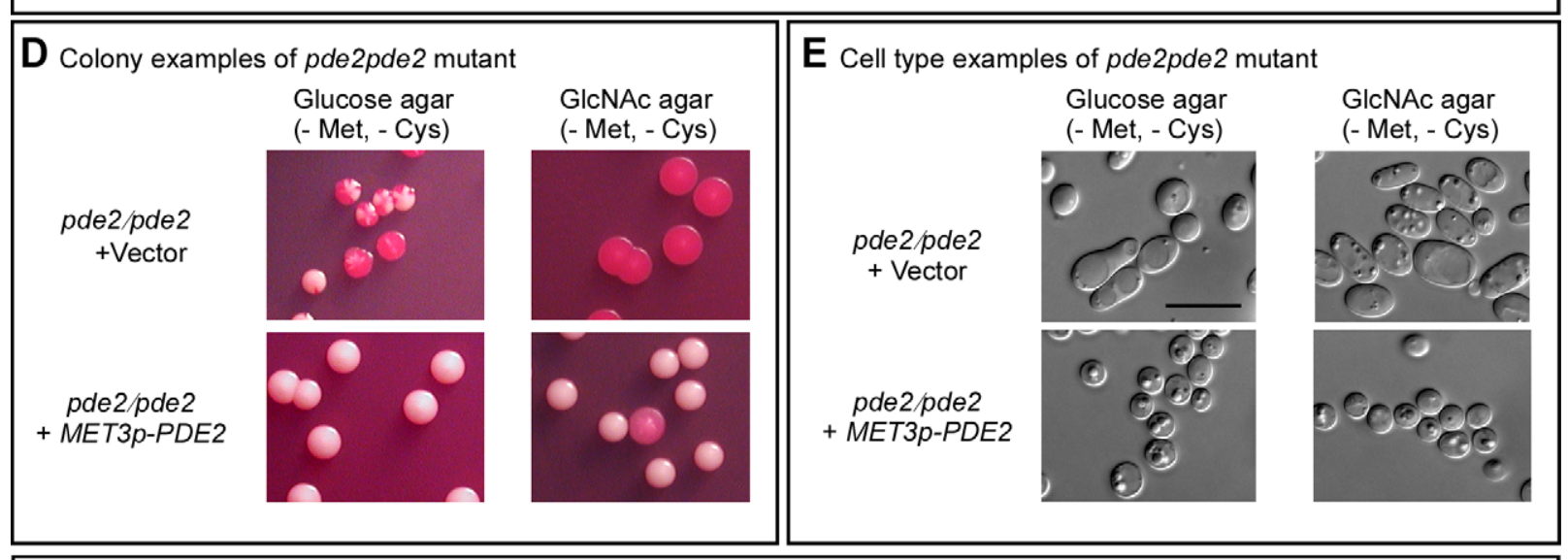

F GlcNAc induction in tpk1/tpk1, tpk2/tpk2 mutants and TPK1, TPK2 overexpression strains

\begin{tabular}{|c|c|c|c|c|c|}
\hline & Glucose & GlcNAc & & Glucose & GlcNAc \\
\hline Strain & Switch. Freq.(\%) & Switch. Freq.(\%) & Strain & Switch. Freq.(\%) & Switch. Freq.(\%) \\
\hline$\overline{\mathrm{WT}}(\mathrm{GH} 1013)$ & $0.6 \pm 0.5$ & $86.9 \pm 4.3$ & $\overline{\text { WT(WUM5A) }}$ & $0.6 \pm 0.6$ & $78.3 \pm 6.5$ \\
\hline tpk1/tpk1 & $0.4 \pm 0.4$ & $80.1 \pm 5.2$ & $\mathrm{WT}+A C T p-T P K 1$ & $0.8 \pm 0.8$ & $0.8 \pm 0.7$ \\
\hline$t p k 2 / t p k 2$ & $0.9 \pm 0.1$ & $94.1 \pm 2.8$ & $\mathrm{WT}+A C T p-T P K 2$ & $62.4 \pm 4.9$ & $97.5 \pm 2.0$ \\
\hline
\end{tabular}

Figure 3. The genes CDC35, PDE2, TPK1 and TPK2 play roles in GICNAc induction of switching. A. Switching frequencies (Switch. Freq.) of cells of the mutants $c d c 35 / c d c 35$ and pde2/pde2 grown at $25^{\circ} \mathrm{C}$ in glucose liquid medium for 7 days (cdc35/cdc35) or 5 days (pde2/pde2), and then plated on glucose or GICNAc agar at $25^{\circ} \mathrm{C}$. The number of assessed colonies ranged between 200 and 450 . B. Streaks of cells grown for 5 days of the parental control strain (WT), the mutant control strain pde2/pde2+vector and the inducible strain pde2/pde2+MET3p-PDE2 under inducing (-Met, -Cyc) and inducing (+Met, +Cys) condition. C. Switching frequencies of cells of the mutant control pde2/pde2+vector and the rescued strain pde2/ pde2+MET3p-PDE2 grown in liquid glucose medium for 2 days and then plated on glucose and GlcNAc agar under activating conditions. The number of assessed colonies ranged between 350 and 450. D. Examples of colonies of $p d e 2 / p d e 2+v e c t o r$ and pde2/pde2+MET3p-PDE2 from panel C under activating conditions. E. Examples of cells from colonies in Figure D. F. Switching frequencies of parental control strains, the mutants tpk1/tpk1 and tpk2/tpk2 and the overexpression strains WT+ACTp-TPK1 and WT+ACTp-TPK2 grown in glucose medium for 5 days and then plated on glucose or GlcNAc agar. The number of assessed colonies ranged between 250 and 800 colonies.

doi:10.1371/journal.ppat.1000806.g003

between amino acids 64 and 69 with a phosphorylatable threonine at amino acid 67 [5].

To test whether Worl was essential for GlcNAc-activated switching, white cells of the parental strain (WT) and the WOR1 deletion mutant worl/worl were grown at $25^{\circ} \mathrm{C}$ to saturation phase (seven days) in liquid glucose medium and then plated on nutrient agar containing glucose or GlcNAc at $25^{\circ} \mathrm{C}$. The worl/ worl mutant did not switch on either glucose or GlcNAc agar 
(Figure 4A, B). Neither a single opaque colony or opaque sector was observed among more than 1,000 colonies. This was also true at $37^{\circ} \mathrm{C}$ (data not shown).

We then tested whether overexpression of WOR1 drove the phenotype to opaque in the ras $1 / \mathrm{ras} 1$, pde2/pde2, cdc35/cdc35, tpk1/tpk1 and tpk2/tpk2 mutants by transforming these mutants with a construct in which WOR1 was under the regulation of the inducible MET3 promoter [33]. In the activated state, $100 \%$ of white cells of all five strains, when plated on either glucose or GlcNAc agar at $25^{\circ} \mathrm{C}$, switched to opaque (Figure $4 \mathrm{C}$ ). These results demonstrated that WOR1 is essential for the induction of switching by GlcNAc and that it plays a role downstream of the Ras1/cAMP pathway.

To test whether threonine phosphorylation is necessary for Worl function, the homozygous deletion mutant wor1/worl was transformed with the WOR1TA construct, in which the phosphorylatable threonine 67 residue was replaced with the nonphosphorylatable amino acid alanine and the construct placed under the control of the inducible tetracycline promoter (TETp) to generate strain wor1/wor1+TETp-WOR1TA. A control strain

\begin{tabular}{|c|c|c|}
\hline A GlcNAc inducti & or1/wor1 & \\
\hline & Glucose & GlcNAc \\
\hline Strain & $\begin{array}{l}\text { Switch. } \\
\text { Freq. (\%) }\end{array}$ & $\begin{array}{l}\text { Switch. } \\
\text { Freq. (\%) }\end{array}$ \\
\hline WOR1MOR1 (WT) & $5.0 \pm 2.2$ & $87.8 \pm 8.9$ \\
\hline wor1/wor1 & $0.0 \pm 0.0$ & $0.0 \pm 0.0$ \\
\hline
\end{tabular}

B Colony examples of wor1/wor1 mutant

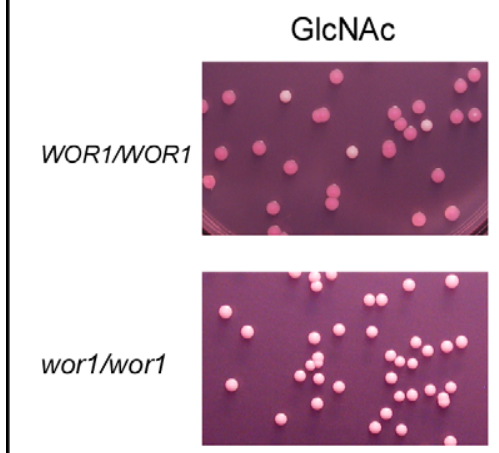

C GlcNAc induction in WOR1 overexpression strains

\begin{tabular}{|c|c|c|c|}
\hline & & Glucose & GlcNAc \\
\hline Strain & & $\begin{array}{l}\text { Switch. } \\
\text { Freq. (\%) }\end{array}$ & $\begin{array}{l}\text { Switch. } \\
\text { Freq. (\%) }\end{array}$ \\
\hline 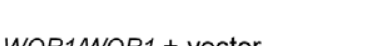 & -Met -Cys & $2.4 \pm 1.1$ & $4.7 \pm 0.9$ \\
\hline WURTINUORT + vecior & + Met+Cys & $0.9 \pm 0.8$ & $3.1 \pm 2.2$ \\
\hline & -Met -Cys & $100.0 \pm 0.0$ & $100.0 \pm 0.0$ \\
\hline WOR1MOR1 +MET3p-WOR1 & + Met+Cys & $0.7 \pm 1.1$ & $5.5 \pm 2.0$ \\
\hline & -Met -Cys & $100.0 \pm 0.0$ & $100.0 \pm 0.0$ \\
\hline ras1/ras1 + MET3p-WOR1 & + Met+Cys & $0.4 \pm 0.6$ & $2.8 \pm 1.3$ \\
\hline $\operatorname{cds} 35 / c d c 35+M E T 3 n-1 N O R 1$ & -Met -Cys & $100.0 \pm 0.0$ & $100.0 \pm 0.0$ \\
\hline 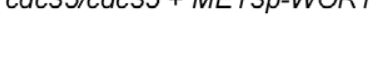 & + Met+Cys & $<0.7$ & $<0.7$ \\
\hline & -Met -Cys & $100.0 \pm 0.0$ & $100.0 \pm 0.0$ \\
\hline$p d e 2 / p d e 2+M E T 3 p-W O R 1$ & + Met+Cys & $90.9 \pm 3.2$ & $100.0 \pm 0.0$ \\
\hline & -Met -Cys & $100.0 \pm 0.0$ & $100.0 \pm 0.0$ \\
\hline tpk1/tpk1 + MET3p-WOR1 & + Met+Cys & $<0.7$ & $1.1 \pm 1.1$ \\
\hline & -Met -Cys & $100.0 \pm 0.0$ & $100.0 \pm 0.0$ \\
\hline$t p k 2 / t p k 2+M E T 3 p-W O R 1$ & + Met+Cys & $<0.7$ & $1.3 \pm 1.2$ \\
\hline
\end{tabular}

D GICNAc induction in WOR1TA overexpression strain

\begin{tabular}{|c|c|c|c|c|}
\hline \multirow[b]{2}{*}{ Strain } & \multicolumn{2}{|c|}{ Doxycyline $(\mu \mathrm{g} / \mathrm{ml})$} & \multirow{2}{*}{$\begin{array}{c}\text { Glucose } \\
\text { Switch. } \\
\text { Freq.(\%) }\end{array}$} & \multirow{2}{*}{$\begin{array}{c}\text { GlcNAc } \\
\text { Switch. } \\
\text { Freq. (\%) }\end{array}$} \\
\hline & $\begin{array}{c}\text { Liquid } \\
\text { medium }\end{array}$ & $\begin{array}{c}\text { Agar } \\
\text { medium }\end{array}$ & & \\
\hline \multirow{2}{*}{ wor1/wor1 + vector } & 50 & 50 & $0.0 \pm 0.0$ & $0.0 \pm 0.0$ \\
\hline & 200 & 200 & $0.0 \pm 0.0$ & $0.0 \pm 0.0$ \\
\hline \multirow{2}{*}{ wor1/wor1 + TETp-WOR1 } & 50 & 50 & $100.0 \pm 0.0$ & $100.0 \pm 0.0$ \\
\hline & 200 & 200 & $100.0 \pm 0.0$ & $100.0 \pm 0.0$ \\
\hline \multirow{2}{*}{ wor1/wor1 + TETp-WOR1TA } & 50 & 50 & $0.0 \pm 0.0$ & $0.0 \pm 0.0$ \\
\hline & 200 & 200 & $0.0 \pm 0.0$ & $(100.0 \pm 0.0$ pink $)$ \\
\hline
\end{tabular}

E Cell type examples of WOR1 and WOR1TA overexpression strains

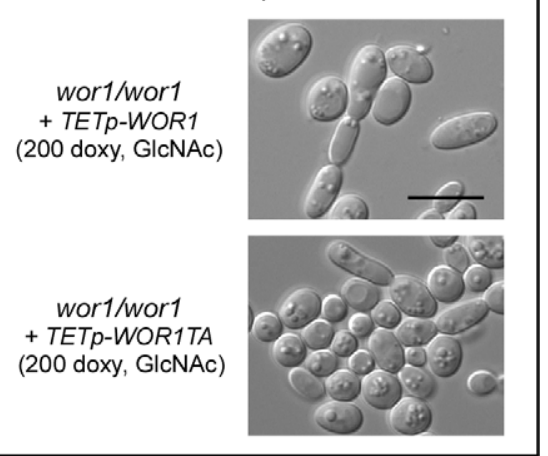

Figure 4. WOR1, the master switch locus, is essential for GICNAc induction and involves phosphorylation. A. Switching frequency of the parental control and mutant wor $1 /$ wor 1 at $25^{\circ} \mathrm{C}$. The number assessed colonies ranged between 250 and 450 . B. Examples of colonies of the control and deletion mutant wor1/wor1 grown at $25^{\circ} \mathrm{C}$ on GICNAC agar. C. Switching frequencies of cells of the control WOR1/WOR1-vector and the overexpression derivatives ras1/ras1+METp-WOR1, cdc35/cdc35+METp-WOR1, pde2/pde2+METp-WOR1, tpk1/tpk1+METp-WOR1 and tpk2/tpk2+METpWOR1 grown at $25^{\circ} \mathrm{C}$ in liquid glucose medium for 1 day and plated on either glucose or GlcNAc agar at $25^{\circ} \mathrm{C}$ under activating conditions (-Met, -Cys). The number assessed colonies ranged between 100 and 400. D. Switching frequencies of cells of the control wor1/wor1-vector, wor1/wor1+TETpWOR1 and wor1/wor1+TETp-WOR1TA grown in glucose liquid medium at $25^{\circ} \mathrm{C}$ and plated on glucose or GlcNAc agar containing 50 or $200 \mu \mathrm{g}$ per ml of doxycycline, the TET inducer, at $25^{\circ} \mathrm{C}$. The number of assessed colonies ranged between 100 and 300 . E. Examples of cells from colonies of cells of wor1/wor1+TETp-WOR1 and wor1/wor1+TETp-WOR1TA grown in glucose liquid medium at $25^{\circ} \mathrm{C}$ and plated on GlcNAc agar containing $200 \mu \mathrm{g}$ of doxycycline at $25^{\circ} \mathrm{C}$.

doi:10.1371/journal.ppat.1000806.g004 
wor1/wor1+TETp-WOR1, was generated in which the mutant wor1/wor1 was transformed with a construct containing the native WOR1 ORF under the regulation of the tetracycline promoter. A second control strain, worl/worl+vector, was also generated in which wor 1/wor1 was transformed with the vector lacking a WOR1 derivative. White cells of the three test strains were grown in liquid glucose medium at $25^{\circ} \mathrm{C}$ to saturation phase (five days) and then plated on glucose or GlcNAc agar at $25^{\circ} \mathrm{C}$. Both the liquid and agar media contained either 50 or $200 \mu \mathrm{g}$ per $\mathrm{ml}$ of the tetracycline analog doxycycline, which had been shown to induce submaximal and maximal levels of expression, respectively [39]. When native WOR1 was overexpressed both in glucose liquid medium and on glucose agar, the switching frequency was $100 \%$ at both 50 and $200 \mu \mathrm{g}$ per $\mathrm{ml}$ of doxycycline (Figure 4D). When WOR1TA was overexpressed in both liquid glucose medium and then after plating on glucose agar at either 50 or $200 \mu \mathrm{g}$ per $\mathrm{ml}$ of doxycycline, the frequency of switching was zero percent (Figure 4D). When native WOR1 was overexpressed in both GlcNAc liquid medium and then after plating on GlcNAc agar at 50 and $200 \mu \mathrm{g}$ per $\mathrm{ml}$ of doxycycline, $100 \%$ of the colonies underwent switching (Figure 4D). At $200 \mu \mathrm{g}$ per ml of doxycycline, over $70 \%$ of the cells in the opaque colonies exhibited the elongate opaque cell phenotype (Figure 4E). When WOR1TA was overexpressed in both GlcNAc liquid medium and then after plating on GlcNAc agar at $50 \mu \mathrm{g}$ per $\mathrm{ml}$ of doxycycline, $0 \%$ of the colonies exhibited switching (Figure 4D). However, when WOR1TA was overexpressed in GlcNAc media at $200 \mu \mathrm{g}$ per ml of doxycycline, $100 \%$ of the colonies were light pink (Figure 4D). Microscopic analysis revealed that $10 \%$ of the cells in these pink colonies exhibited the elongate opaque phenotype (Figure 4E). These results suggested that expression of the unphosphorylatable derivative of Wor1, Wor1TA, was capable of inducing switching, but with a 10 -fold reduction in efficiency.

Because WOR1 and WOR1TA were fused in frame with GFP in the overexpression mutants, we used confocal microscopy to test whether Wor1TA localized normally to the nucleus and was expressed at the same level as Worl. Both Worl and WorlTA localized to the nucleus of a majority of cells of the overexpression mutants treated with doxycycline, as demonstrated by overlapping GFP fluorescence and staining with DAPI, a DNA indicator (Figure 5A). Moreover, GFP fluorescence of nuclei was qualitatively comparable for Wor 1-GFP and Wor1TA-GFP (Figure 5A). These results demonstrated that although the replacement of threonine with alanine caused a dramatic decrease in its capacity to support switching, it did not affect nuclear localization or cause a decrease in the transcript level. The levels of the Worl and WorlTA protein were then compared by western blot analysis using anti-GFP antibody. The levels of Worl and WorlTA expressed in white cells of strains wor1/wor1+TETp-WOR1 and wor1/wor1+TETp-WOR1TA, respectively, treated with $200 \mu \mathrm{g}$ per $\mathrm{ml}$ of doxycycline were similar (Figure $5 \mathrm{~B}$ ). These results indicate that the decrease in Wor 1 function resulting from the replacement of threonine with alanine in the PKA consensus motif of Wor 1 was due to a decrease in function, rather than to a decrease in the level of the Worl protein or mis-localization.

\section{Low $\mathrm{CO}_{2}$ Enhances GlcNAc Induction}

We had demonstrated that $1 \% \mathrm{CO}_{2}$ induced switching submaximally and that at this concentration induction was dependent primarily upon the Rasl/cAMP signal transduction pathway [18]. We have shown here that GlcNAc induction was also submaximal when cells were grown for only two days in glucose liquid medium to mid-log phase (Figure 1C, D). We therefore tested whether cells growing at 25 or $37^{\circ} \mathrm{C}$ in a suboptimal concentration of $\mathrm{CO}_{2}(1 \%)$ and for a suboptimal period of time in glucose liquid medium enhanced GlcNAc induction. White cells of an $\mathbf{a} / \mathbf{a}$ and an $\alpha / \alpha$ strain were first grown at $25^{\circ} \mathrm{C}$ in glucose liquid medium in air for two days and then plated on either glucose or GlcNAc agar either in air or in air containing $1 \% \mathrm{CO}_{2}$ at 25 or $37^{\circ} \mathrm{C}$. On glucose agar in $1 \% \mathrm{CO}_{2}$ at both temperatures, cells of the $\mathbf{a} / \mathbf{a}$ and $\alpha / \alpha$ strains exhibited switching frequencies that were significantly higher than in air

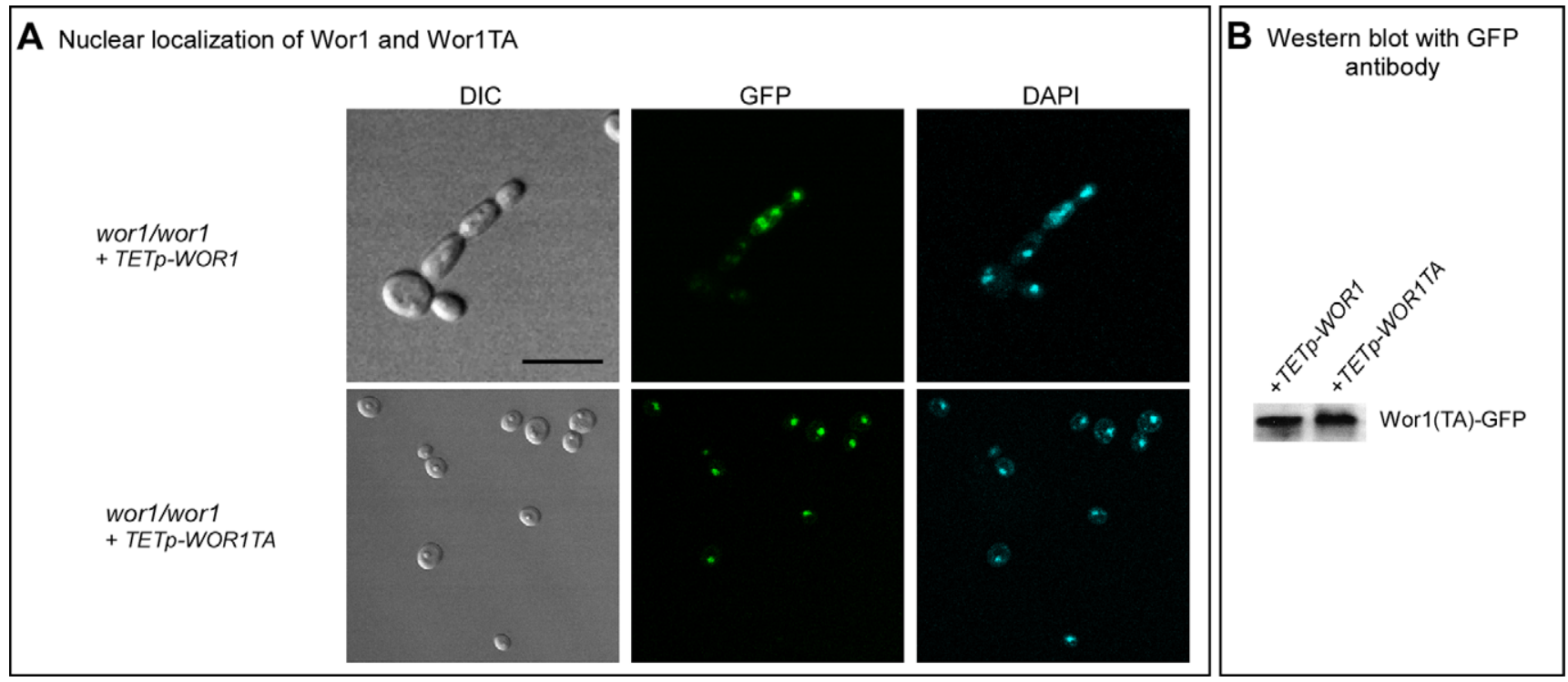

Figure 5. Wor1 localizes to the nucleus in the phosphorylated and unphosphorylated state. A. GFP fluorescence of Wor1 and Wor1TA, in parallel with DAPI staining of nuclei, of strains wor1/Wor1+TETp-WOR1 and wor1/wor1+TETp-WOR1TA, respectively. Cells were grown in glucose liquid medium containing $200 \mu \mathrm{g}$ per $\mathrm{ml}$ of doxycycline at $25^{\circ} \mathrm{C}$. B. Western blot analysis of Wor 1 and Wor1TA using anti-GFP antibody in strains wor $1 /$ wor1+TETp-WOR1 and wor1/wor1+TETp-WOR1TA. Protein extracts were derived from cells grown at $25^{\circ} \mathrm{C}$ in glucose liquid medium containing $200 \mu \mathrm{g}$ per $\mathrm{ml}$ of doxycycline.

doi:10.1371/journal.ppat.1000806.g005 
alone (Table 1). When plated on GlcNAc agar in air at $25^{\circ} \mathrm{C}$, the respective frequencies of the two strains were $26.7 \pm 1.2 \%$ and $22.4 \pm 3.3 \%$, but at $37^{\circ} \mathrm{C}$, they were $98.9 \pm 2 \%$ and $99.7 \pm 0.6 \%$. However, when plated on GlcNAc agar in $1 \% \mathrm{CO}_{2}$, the switching frequency at the two temperatures were 99 to $100 \%$ in both strains (Table 1). These results indicate synergy for $\mathrm{CO}_{2}$ and GlcNAc induction, and enhancement by physiological temperature.

\section{Discussion}

Recently, high $\mathrm{CO}_{2}$ was demonstrated to be a potent inducer of the white-opaque transition at $37^{\circ} \mathrm{C}$ [18]. The high concentrations of $\mathrm{CO}_{2}$ that induce and maintain the opaque phenotype at $37^{\circ} \mathrm{C}$ are found in select host tissues and in the gastrointestinal tract $[40,41]$. The main source of $\mathrm{CO}_{2}$ in the gastrointestinal tract is the result of metabolism by colonic bacteria [40]. Here, we demonstrate GlcNAc, also a product primarily of bacteria that cohabit the host gastrointestinal tract with C. albicans [21-23,42] represents a second potent inducer of the white to opaque transition.

By mutational analyses, we have found that the components of the Ras1/cAMP pathway, Ras1, Cdc35, Pde2 and PKA (Tpk1, Tpk2), mediate the major portion of GlcNAc induction. Our results also indicate that switching in glucose medium, which is at a far lower frequency than that in GlcNAc medium, is mediated in part by the Ras1/cAMP pathway. The low level of induction in deletion mutants of the Ras1/cAMP pathway is still approximately ten-fold higher than the level caused by glucose in wild type cells. Because the pathway that transduces high $\mathrm{CO}_{2}$ induction is also Ras1/cAMP-independent and unidentified, the possibility must be entertained that it may be the same Rasl/cAMP-independent pathway that mediates the minor portion of GlcNAc induction.

Our results, especially those at $37^{\circ} \mathrm{C}$, suggest that the PKA isoform Tpk2 functions as the major downstream target of cAMP in the GlcNAc response pathway. Tpkl appears to be capable of substituting for Tpk2 in the mutant tpk2/tpk2, but when overexpressed, inhibits GlcNAc-induced switching. One possible explanation is that the two Tpk isoforms play inhibiting and stimulating roles, respectively, in the white to opaque transition, especially in light of the fact that Efgl, a negative regulator of Worl [8], contains a PKA phosphorylation site. Tpk isoforms have been found to play different roles in the same regulatory networks in other systems. In S. cerevisiae, while Tpk2 activates filamentation downstream of cAMP in the glucose induced pathway, Tpk1 and Tpk3 inhibit filamentation by a feedback loop [36]. In addition, in the pheromone response pathway of $C$. albicans, the downstream MAP kinases Cek1 and Cek2 also play both distinct and overlapping roles [43], suggesting a general pattern of functional complexity of downstream protein kinase isoforms in signal transduction pathways.

Mutant analysis revealed that both the major and minor GlcNAc induction pathways required the master switch locus WOR1. Because cAMP activates PKA, we considered the possibility that Worl, which contains one conserved PKA phosphorylation motif between amino acids 64 and 69, might have to be phosphorylated to function in the switch event. By converting the single threonine residue at that site to alanine, GlcNAc induction was impaired dramatically, indicating that phosphorylation of threonine 67 of Worl is necessary for maximum induction by GlcNAc. The observation that GlcNAc induction was completely blocked in the wor1/wor1 mutant, but only impaired in the wor1/wor1+TETp-WOR1TA mutant suggested that the constitutively unphosphorylated form of Wor 1 was still functional, but at far lower efficiency than the phosphorylated form. In Schizosaccharomyces pombe, the gluconate transport inducer 1 (Gtil), an ortholog of Worl, also harbors one conserved PKA phosphorylation motif between amino acids 65 and 70, and conversion of the single threonine residue at that site to alanine causes severe impairment of function [44]. As is the case in $C$. albicans, Pkal, which is the only PKA in S. pombe, is involved in the regulation of Gtil. Given that in C. albicans, Worl has one conserved PKA phosphorylation site that must be phosphorylated to attain the major portion of GlcNAc induction, and that Tpk2 appears to be the downstream PKA involved in GlcNAc induction, it seems reasonable to suggest that GlcNAc induction may involve the direct phosphorylation of Wor 1 by Tpk2, but that remains to be demonstrated.

The Rasl/cAMP-dependent pathway has been found to be the predominant one for GlcNAc induction and the minor one for low level $\mathrm{CO}_{2}$ induction [18] (Figure 6). An unidentified pathway has been found to be the predominant one for $\mathrm{CO}_{2}$ induction [18] and an unidentified pathway has the minor one for GlcNAc induction (Figure 6). Our data further suggest that glucose represents a weak but significant inducer of switching that also functions through both a Ras1/cAMP-dependent pathway and a Ras1/cAMPindependent pathway, the latter again unidentified (Figure 6). The fact that each inducer functions not only through the Ras 1/cAMP pathway, but also through an unidentified pathway, leaves open the possibility that the Rasl/cAMP-independent pathway may also be common to all three inducers. We demonstrated previously that both the Ras1/cAMP-dependent and -independent pathways for $\mathrm{CO}_{2}$ induction are dependent on Worl [18], and we have demonstrated here that the dependent and independent pathways for G1cNAc and glucose induction are also dependent on Worl. We have demonstrated that only the major portion of GlcNAc induction, which is transduced by the Ras1/cAMP pathway, requires the phosphorylated form of Worl.

The induction of switching by environmental cues shares several characteristics with that of filamentation. First, both $\mathrm{CO}_{2}$ and GlcNAc induce filamentation [19,20,24] as they do switching. Second, the Ras1/cAMP pathway has been demonstrated to play a role in the induction of filamentation by $\mathrm{CO}_{2}$ [20], as it does in switching. The Ras1/cAMP pathway has also been demonstrated to play a role in the induction of filamentation in $S$. cerevisiae $[36,45]$, suggesting that the pathways regulating of filamentation represent an ancestral process conserved in the evolution of both the Candida and Saccharomyces groups of the hemiascomycetes. Several characteristics of the opaque phenotype are shared with hyphae, including an elongate shape, a prominent vacuole and cell surface antigens [46,47]. Because white-opaque switching is a specific and unique characteristic of $C$. albicans and the closely related species Candida dubliniensis [48], it represents a newly evolved developmental process, in contrast to filamentation.

Switching of C. albicans from white to opaque at physiological temperature can therefore be influenced by two factors in the gastrointestinal tract that result primarily from gastrointestinal bacteria: high $\mathrm{CO}_{2}$ [18] and free GlcNAc. In host tissue, high $\mathrm{CO}_{2}$ is the result of metabolism by the host, but in the gastrointestinal tract, it is the product of bacterial metabolism $[40,41]$. GlcNAc in the gastrointestinal tract is also a product primarily of gastrointestinal tract bacteria, but also to a lesser extent of host goblet cells [41]. Hence, bacteria of the gastrointestinal tract produce two potent inducers of the white to opaque transition, a prerequisite for mating between $\mathbf{a} / \mathbf{a}$ and $\alpha / \alpha$ cells [4]. These results suggest that two developmental programs of $C$. albicans, filamentation and switching, have evolved to respond to signals originating from bacterial co-members of the gastrointestinal microbiota. 


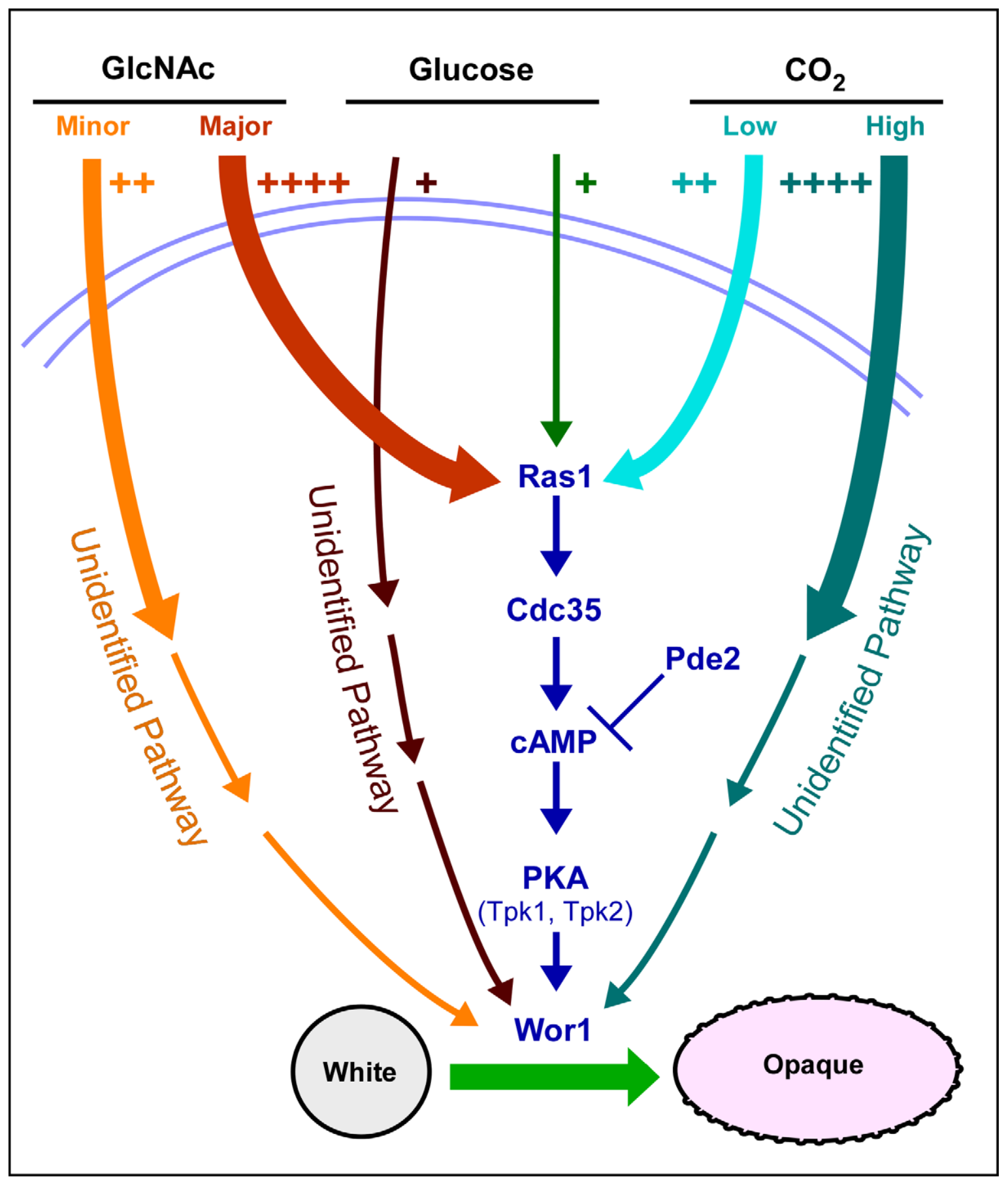

Figure 6. A model of the regulatory circuitry involved in the induction of the white to opaque switch. The number of plus signs and the thickness of initial pathway arrows reflect the degree of induction. Note that we have all pathways converging on the master switch gene WOR1 because of their dependency on that gene. doi:10.1371/journal.ppat.1000806.g006

\section{Materials and Methods}

\section{Strain Maintenance and Growth}

The strains of $C$. albicans used in this study are listed in supplemental Table S2. For routine growth, modified Lee's medium without methionine was used [31], unless stated otherwise. For repression of MET3 promoter-controlled gene expression, $2.5 \mathrm{mM}$ methionine and $2.5 \mathrm{mM}$ cysteine were added to the medium. For GlcNAc induction, the carbon source glucose was replaced with GlcNAc $(1.25 \% \mathrm{w} / \mathrm{v})$ in nutrient medium.
Here, agar containing Lee's medium, in which glucose was the carbon source, was referred to as glucose agar and Lee's medium containing GlcNAc as a carbon source was referred to as GlcNAc agar. Agar cultures were grown at a density of 80-120 colonies per $85 \mathrm{~mm}$ plate. Phloxine B was added to nutrient agar for opaque colony staining [46].

\section{Construction of $C$. albicans Deletion Mutants}

The PDE2 gene was disrupted using a modified Ura-blaster method [49]. Two long primers (PDE2-5DR, PDE2-3DR), each 
containing a different 60 nucleotide sequence homologous to the gene PDE2, were used for PCR amplification (supplemental Table S3). pDDB57, which contains the recyclable URA3-dpl200 marker, was used as template. The PCR product was transformed into WUM5A, a WO-1 derivative [50]. Transformants were grown on selective synthetic defined (SD) medium SD-Ura agar plates. To delete the second allele of PDE2, the PCR product was transformed into a spontaneous Ura- derivative of $P D E 2 / p d e 2$ obtained from SD agar containing 5-fluoro-orotic acid. pde2/pde2 null mutants were selected from SD-Ura agar plates and confirmed by PCR.

TPK1 and TPK2 were deleted by a PCR product-directed disruption protocol, as described in [18]. Briefly, the HIS1 and ARG4 markers were amplified by PCR from pGEM-HIS1 and pRS-ARG4-SpeI, respectively. The oligonucleotide pairs TPK15DR, TPK1-3DR; TPK2-5DR, TPK2-3DR (supplemental Table S3) were used for PGR amplification. The HIS1 and ARG4 markers were sequentially transformed into the host strains GH1013 [51], and heterozygous mutants. The null mutants were selected on SD-His-Arg plates and confirmed by PCR.

\section{Construction of Plasmids}

The primers used for plasmid constructions are listed in supplemental Table S3. To generate pMET-RAS1V13, the RAS1 ORF containing a mutation at the thirteenth amino acid (glycine to valine mutation) was amplified from pQF145.2 [25] by using primers including $P s t \mathrm{I}$ and $S p h \mathrm{I}$ sites, and then cloned into pCaEXP [33]. pMET-CDC35 was constructed by inserting the BamHI-SphI digested CDC35 ORF fragment into pCaEXP. To generate pMET-PDE2, the PDE2 ORF was amplified from CAI4 genomic DNA by using the primers PDE2F and PDE2R that contained BamHI and SphI sites (supplemental Table S3) and the PDE2 ORF was cloned into pCaEXP. To generate pACT-TPK1, the TPK1 ORF was amplified from CAI4 genomic DNA by using the primers TPK $1 \mathrm{~F}$ and TPK $1 \mathrm{R}$ that included $E c o \mathrm{RV}$ and HindIII sites (supplemental Table S3), and the TPK1 ORF was cloned into pACT1 [18]. The TPK2 ORF was amplified from CAI4 genomic DNA by using primers TPK2F and TPK2R (supplemental Table S3). To generate pACT-TPK2, the PCR product was digested by HindIII and cloned into EcoRV/HindIII-digested pACT1. pNIMWOR 1 was constructed by inserting a SalI digested PCR fragment of WOR1 into the SalI site of pNIM1 [52]. The WOR1 ORF was amplified from CAI4 genomic DNA. The primers WOR 1 salF and WOR 1 salR were used for PCR amplification (supplemental Table $\mathrm{S} 3)$. To generate a mutation in which threonine 67 is replaced with alanine in the WOR1 gene, a two-step PCR method [53] was used with slight modification. The primers WOR1TAF and WOR1TAR (supplemental Table S3) were used to generate sitedirected mutation. The second-round PCR product was digested with $S a l I$ and subcloned into the SalI site of pNIM1. The resulting plasmid was referred to as pNIM-WOR1TA. The correct direction of WOR1 ORF and WOR1TA fragment in pNIM1 was confirmed by sequencing.

\section{Regular White-Opaque Switching Assay (from Agar to Agar)}

White-opaque switching on agar was analyzed as described previously [15]. Briefly, strains were first grown on agar containing supplemented Lee's medium for 6 days at $25^{\circ} \mathrm{C}$. Colonies were then replated onto plates containing supplemented Lee's medium [31]. These plates were then incubated at $25^{\circ} \mathrm{C}$ for five days, and the proportion of colonies exhibiting different phenotypes counted.

\section{White to Opaque Switching of Cells in Different Growth Phases}

White colonies were inoculated into a test tube containing $1 \mathrm{ml}$ of supplemented Lee's medium [31] with glucose as carbon source and incubated at $25^{\circ} \mathrm{C}$. The overnight culture was diluted (to $2 \times 10^{5} \mathrm{cells} / \mathrm{ml}$ ) in $20 \mathrm{ml}$ of fresh medium with glucose as the carbon source and incubated at $22^{\circ} \mathrm{C}$ in a shaker. Aliquots were taken out at different time points, diluted and plated onto both glucose agar and GlcNAc agar plates (Figure 1A). The plates were then incubated at $25^{\circ} \mathrm{C}$ for five days, and the colonies exhibiting different colony phenotypes counted. For the experiments performed at $37^{\circ} \mathrm{C}$, plates were cultured at both 25 and $37^{\circ} \mathrm{C}$.

\section{Western Blot Analysis}

Cells from liquid cultures were spun down following doxycycline treatment for 12 hours. Total protein extract was obtained using a bead beater in lysis buffer that contained $50 \mathrm{mM}$ Tris-HCl, $100 \mathrm{mM} \mathrm{NaCl}, 5 \mathrm{mM} \mathrm{MgCl}$, $1 \mathrm{mM}$ DTT, $1 \mathrm{mM}$ EDTA, $1 \mathrm{mM}$ EGTA, 0.1\% Tween-20, and 5\% glycerol, supplemented with a protease inhibitor cocktail (Sigma-Aldrich, St Louis, MO) and $1 \mathrm{mM}$ phenyl-methylsulphonyl fluoride. An equal amount of total protein from each sample was then subjected to protein $G$ beads (Active Motif, Carlsbad, California) for pre-clearing, followed by immuno-precipitation (IP) using rabbit GFP antibody-conjugated agarose beads (Santa Cruz Biotechnology, Santa Cruz, California). IP protein samples were subjected to SDS-PAGE (8\% polyacrylamide) electrophoresis. After electrophoresis, the SDS-PAGE protein gel was transferred to a PVDF membrane (Immobilon-P, Millipore Corporation, Bedford, MA), blocked for $1 \mathrm{~h}$ in $3 \%$ nonfat dry milk in TBS-T (20 mM Tris-HCl, pH 7.5, $150 \mathrm{mM} \mathrm{NaCl}$, $0.05 \%$ Tween-20), and then incubated with rabbit polyclonal GFP antibody (Santa Cruz Biotechnology, Santa Cruz, CA) overnight at $4^{\circ} \mathrm{C}$ [54]. After washing six times in TBS-T, the proteins on the membrane were detected with horseradish peroxidase-labelled goat anti-rabbit IgG (Promega, Madison, WI) and SuperSignal West Pico Chemiluminescent Substrate (Pierce, Rockford, IL).

\section{Co-localization of GFP-Wor1p and Nuclei}

Cells expressing tetracycline (doxycycline)-inducible GFP-labeled Worlp were grown to midlog phase in the presence of $50 \mu \mathrm{g} / \mathrm{ml}$ doxycycline (Sigma-Aldrich, St Louis, MO, USA), harvested and simultaneously permeabilized and the nuclei labeled with 4',6'-Diamidino-2-phenylindole (DAPI, Invitrogen, Inc.) by incubating them for $10 \mathrm{~min}$ at room temperature in the dark in a solution containing $5 \mu \mathrm{g} / \mathrm{ml}$ DAPI in $1 \mathrm{M}$ Sorbitol, $0.1 \%$ Saponin, $150 \mathrm{mM} \mathrm{NaCl}$ and $20 \mathrm{mM}$ Tris buffer, $\mathrm{pH}$ 7.4, followed by a 15-20 min incubation period on ice. Without washing, the cells were imaged using a Bio-Rad Radiance $2100 \mathrm{MP}$ multiphoton microscope (Bio-Rad, Hermel, Hamstead, UK). Cells were excited at $780 \mathrm{~nm}$ by a Mai-Tai laser (Spectra- Physics, Newport Corp., Mountain View, CA) and three channel emission images (GFP, DAPI and transmitted) were gathered using a sequential $2.0 \mu \mathrm{m} \mathrm{Z}$-series, gathered at $0.2 \mu \mathrm{m}$ intervals to include the entire cell nucleus. GFP and DAPI images were visualized as Z-series projections. Transmitted images were a single scan at the focal plane selected from the Z-series.

\section{Supporting Information}

Table S1 Ras1/cAMP pathway is required for GlcNAc induction of white to opaque switching at $37^{\circ} \mathrm{C}$.

Found at: doi:10.1371/journal.ppat.1000806.s001 (0.03 MB DOC) 
Table S2 Strains used in this study.

Found at: doi:10.1371/journal.ppat.1000806.s002 (0.04 MB DOC)

Table S3 Primers used in this study.

Found at: doi:10.1371/journal.ppat.1000806.s003 (0.04 MB DOC)

\section{Acknowledgments}

The authors are indebted to Drs. Joachim Morschhäuser at the University of Würtsburg, Germany and Gerald R. Fink at the Whitehead Institute for

\section{References}

1. Soll DR (1992) High-frequency switching in Candida albicans. Clin Microbiol Rev 5: $183-203$.

2. Soll DR (2009) Why does Candida albicans switch? FEMS Yeast 9: 973-89.

3. Lan CY, Newport G, Murillo LA, Jones T, Scherer S, et al. (2002) Metabolic specialization associated with phenotypic switching in Candida albicans. Proc Natl Acad Sci U S A 99: 14907-14912.

4. Miller MG, Johnson AD (2002) White-opaque switching in Candida albicans is controlled by mating-type locus homeodomain proteins and allows efficient mating. Cell 110: 293-302.

5. Huang G, Wang H, Chou S, Nie X, Chen J, et al. (2006) Bistable expression of WOR1, a master regulator of white-opaque switching in Candida albicans. Proc Natl Acad Sci U S A 103: 12813-12818.

6. Srikantha T, Borneman AR, Daniels KJ, Pujol C, Wu W, et al. (2006) TOS9 regulates white-opaque switching in Candida albicans. Eukaryot Cell 5: 1674-1687.

7. Zordan RE, Galgoczy DJ, Johnson AD (2006) Epigenetic properties of whiteopaque switching in Candida albicans are based on a self-sustaining transcriptional feedback loop. Proc Natl Acad Sci U S A 103: 12807-12812.

8. Zordan RE, Miller MG, Galgoczy DJ, Tuch BB, Johnson AD (2007) Interlocking transcriptional feedback loops control white-opaque switching in Candida albicans. PLoS Biol 5(10): e256. doi:10.1371/journal.pbio.0050256.

9. Vinces MD, Kumamoto CA (2007) The morphogenetic regulator Czflp is a DNA-binding protein that regulates white opaque switching in Candida albicans. Microbiology 153: 2877-2884.

10. Klar AJ, Srikantha T, Soll DR (2001) A histone deacetylation inhibitor and mutant promote colony-type switching of the human pathogen Candida albicans. Genetics 158: 919-924.

11. Srikantha T, Tsai L, Daniels K, Klar AJ, Soll DR (2001) The histone deacetylase genes HDA1 and RPD3 play distinct roles in regulation of high-frequency phenotypic switching in Candida albicans. J Bacteriol 183: 4614-4625.

12. Hnisz D, Schwarzmuller T, Kuchler K (2009) Transcriptional loops meet chromatin: a dual-layer network controls white-opaque switching in Candida albicans. Mol Microbiol 74: 1-15.

13. Hull CM, Johnson AD (1999) Identification of a mating type-like locus in the asexual pathogenic yeast Candida albicans. Science 285: 1271-1275.

14. Lockhart SR, Pujol C, Daniels KJ, Miller MG, Johnson AD, Pfaller MA, Soll DR (2002) In Candida albicans, white-opaque switchers are homozygous for mating type. Genetics 162: 737-745.

15. Slutsky B, Staebell M, Anderson J, Risen L, Pfaller M, Soll DR (1987) "Whiteopaque transition": a second high-frequency switching system in Candida albicans. J Bacteriol 169: 189-197.

16. Rikkerink EH, Magee BB, Magee PT (1988) Opaque-white phenotype transition: a programmed morphological transition in Candida albicans. J Bacteriol 170: 895-899.

17. Srikantha T, Soll DR (1993) A white-specific gene in the white-opaque switching system of Candida albicans. Gene 131: 53-60.

18. Huang G, Srikantha T, Sahni N, Yi S, Soll DR (2009) $\mathrm{CO}_{2}$ regulates white-toopaque switching in Candida albicans. Curr Biol 19: 330-334.

19. Mock RC, Pollack JH, Hashimoto T (1990) Carbon dioxide induces endotrophic germ tube formation in Candida albicans. Can J Microbiol 36: 249-253.

20. Klengel T, Liang WJ, Chaloupka J, Ruoff C, Schroppel K, et al. (2005) Fungal adenylyl cyclase integrates $\mathrm{CO}_{2}$ sensing with cAMP signaling and virulence. Curr Biol 15: 2021-2026.

21. Ghuysen J.-M, Hakenbeck R (1994) Bacterial cell wall. Amsterdam: Elsevier. 581 p.

22. Simonetti N, Strippoli V, Cassone A (1974) Yeast-mycelial conversion induced by N-acetyl-D-glucosamine in Candida albicans. Nature 250: 344-346.

23. Cho T, Hamatake H, Kaminishi H, Hagihara Y, Watanabe K (1992) The relationship between cyclic adenosine $3^{\prime}, 5^{\prime}$-monophosphate and morphology in exponential phase Candida albicans. J Med Vet Mycol 30: 35-42.

24. Cassone A, Sullivan PA, Shepherd MG (1985) N-acetyl-D-glucosamine-induced morphogenesis in Candida albicans. Microbiologica 8: 85-99.

25. Feng Q, Summers E, Guo B, Fink G (1999) Ras signaling is required for seruminduced hyphal differentiation in Candida albicans. J Bacteriol 181: 6339-6346.

26. Rocha CR, Schroppel K, Harcus D, Marcil A, Dignard D, et al. (2001) Signaling through adenylyl cyclase is essential for hyphal growth and virulence in the pathogenic fungus Candida albicans. Mol Biol Cell 12: 3631-3643.
Biomedical Research, Massachusetts Institute of Technology, for generous gifts of plasmids and strains.

\section{Author Contributions}

Conceived and designed the experiments: DRS. Performed the experiments: GH SY NS KJD TS. Analyzed the data: DRS. Wrote the paper: GH DRS. Made figures: KJD.
27. Bockmühl DP, Krishnamurthy S, Gerads M, Sonneborn A, Ernst JF (2001) Distinct and redundant roles of the two protein kinase A isoforms Tpklp and Tpk2p in morphogenesis and growth of Candida albicans. Mol Microbiol 42: 1243-1257.

28. Castilla R, Passeron S, Cantore ML (1998) N-acetyl-D-glucosamine induces germination in Candida albicans through a mechanism sensitive to inhibitors of cAMP-dependent protein kinase. Cell Signal 10: 713-719.

29. Bahn YS, Molenda M, Staab JF, Lyman CA, Gordon LJ, et al. (2007) Genomewide transcriptional profiling of the cyclic AMP-dependent signaling pathway during morphogenic transitions of Candida albicans. Eukaryot Cell 6: 2376-2390.

30. Wilson D, Tutulan-Cunita A, Jung W, Hauser NC, Hernandez R, et al. (2007) Deletion of the high-affinity cAMP phosphodiesterase encoded by PDE2 affects stress responses and virulence in Candida albicans. Mol Microbiol 65: 841-856.

31. Bedell GW, Soll DR (1979) Effects of low concentrations of zinc on the growth and dimorphism of Candida albicans: evidence for zinc-resistant and -sensitive pathways for mycelium formation. Infect Immun 26: 348-354

32. Bergen MS, Voss E, Soll DR (1990) Switching at the cellular level in the whiteopaque transition of Candida albicans. J Gen Microbiol 136: 1925-1936.

33. Care RS, Trevethick J, Binley KM, Sudbery PE (1999) The MET3 promoter: a new tool for Candida albicans molecular genetics. Mol Microbiol 34: 792-798.

34. Bahn YS, Staab J, Sundstrom P (2003) Increased high-affinity phosphodiesterase $P D E 2$ gene expression in germ tubes counteracts CAP1-dependent synthesis of cyclic AMP, limits hypha production and promotes virulence of Candida albicans. Mol Microbiol 50: 391-409.

35. Jung WH, Stateva LI (2003) The cAMP phosphodiesterase encoded by CaPDE2 is required for hyphal development in Candida albicans. Microbiology 149: 2961-2976.

36. Pan X, Harashima T, Heitman J (2000) Signal transduction cascades regulating pseudohyphal differentiation of Saccharomyces cerevisiae. Curr Opin Microbiol 3: $567-572$.

37. Nikawa J, Cameron S, Toda T, Ferguson KM, Wigler M (1987) Rigorous feedback control of cAMP levels in Saccharomyces cerevisiae. Genes Dev 1: 931-937.

38. Cloutier M, Castilla R, Bolduc N, Zelada A, Martineau P, et al. (2003) The two isoforms of the cAMP-dependent protein kinase catalytic subunit are involved in the control of dimorphism in the human fungal pathogen Candida albicans. Fungal Genet Biol 38: 133-141.

39. Sahni N, Yi S, Daniels KJ, Srikantha T, Pujol C, et al. (2009) Genes Selectively Up-Regulated by Pheromone in White Cells Are Involved in Biofilm Formation in Candida albicans. PLoS Pathog 5(10): e1000601. doi:10.1371/journal.ppat. 1000601.

40. Levitt MD, Bond JH, Jr. (1970) Volume, composition, and source of intestinal gas. Gastroenterology 59: 921-929.

41. Avunduk C (2002) Manual of Gastroenterology: Diagnosis and Therapy. Philadelphia: Lippincott Williams \& Wilkins. 505 p.

42. O'Hara AM, Shanahan F (2006) The gastrointestinal tract flora as a forgotten organ. EMBO Rep 7: 688-693.

43. Chen J, Chen J, Lane S, Liu H (2002) A conserved mitogen-activated protein kinase pathway is required for mating in Candida albicans. Mol Microbiol 46: 1335-1344.

44. Caspari T (1997) Onset of gluconate-H+ symport in Schizosaccharomyces pombe is regulated by the kinases Wis 1 and Pkal, and requires the gtil+ gene product. J Cell Sci 110: 2599-2608.

45. Madhani HD, Fink GR (1998) The control of filamentous differentiation and virulence in fungi. Trends Cell Biol 8: 348-353.

46. Anderson JM, Soll DR (1987) Unique phenotype of opaque cells in the whiteopaque transition of Candida albicans. J Bacteriol 169: 5579-5588.

47. Anderson J, Mihalik R, Soll DR (1990) Ultrastructure and antigenicity of the unique cell wall pimple of the Candida opaque phenotype. J Bacteriol 172: $224-235$.

48. Pujol C, Daniels KJ, Lockhart SR, Srikantha T, Radke JB, et al. (2004) The closely related species Candida albicans and Candida dubliniensis can mate. Eukaryot Cell 3: 1015-1027.

49. Wilson RB, Davis D, Enloe BM, Mitchell AP (2000) A recyclable Candida albicans URA3 cassette for PCR product-directed gene disruptions. Yeast 16: 65-70. 
50. Strauss A, Michel S, Morschhäuser J (2001) Analysis of phase-specific gene expression at the single-cell level in the white-opaque switching system of Candida albicans. J Bacteriol 183: 3761-3769.

51. Wilson RB, Davis D, Mitchell AP (1999) Rapid hypothesis testing with Candida albicans through gene disruption with short homology regions. J Bacteriol 181: 1868-1874.
52. Park YN, Morschhüuser J (2005) Tetracycline-inducible gene expression and gene deletion in Candida albicans. Eukaryot Cell 4: 1328-1342.

53. Ke SH, Madison EL (1997) Rapid and efficient site-directed mutagenesis by single-tube 'megaprimer' PCR method. Nucleic Acids Res 25: 3371-3372.

54. Yi S, Sahni N, Pujol C, Daniels KJ, Srikantha T, et al. (2009) A Candida albicansspecific region of the alpha-pheromone receptor plays a selective role in the white cell pheromone response. Mol Microbiol 71: 925-947. 